\title{
Treatment with phosphodiester CpG-ODN ameliorates atopic dermatitis by enhancing TGF- $\beta$ signaling
}

\author{
Won-Kook Ham ${ }^{1}$, Eun-Jung Lee ${ }^{1}$, Myung Shin Jeon ${ }^{2}$, Hae-Young Kim ${ }^{1}$, Gaurav Agrahari ${ }^{1}$, Eun-Joo An ${ }^{1}$, Chul Hwan Bang ${ }^{1}$, \\ Doo-Sik Kim ${ }^{3}$ E Tae-Yoon Kim ${ }^{1, *}$ \\ ${ }^{1}$ Department of Dermatology, College of Medicine, The Catholic University of Korea, Seoul 06591, ${ }^{2}$ Translational Research Center, \\ Department of Molecular Biomedicine, IRIMS, and College of Medicine, Inha University, Incheon 22212, ${ }^{3}$ Department of Biochemistry, \\ College of Life Science and Biotechnology, Yonsei University, Seoul 03722, Korea
}

\begin{abstract}
Synthetic oligodeoxynucleotides (ODNs) containing unmethylated CpG phosphorothioate (PS CpG-ODN) are known to decrease lgE synthesis in Th2 allergy responses. Nonetheless, the therapeutic role of PS CpG-ODN is limited due to cytotoxicity. Therefore, we developed a phosphodiester (PO) form of CpG-ODN (46O) with reduced toxicity but effective against allergies. In this study, we first compared the toxicity of 460 with CpG-ODNs containing a PS backbone (1826S). We also investigated the therapeutic efficacy and mechanism of 460 injected intravenously in a mouse model of ovalbumin (OVA)induced atopic dermatitis (AD). To elucidate the mechanism of 460 underlying the inhibition of IgE production, IgE- and TGF- $\beta$-associated molecules were evaluated in CD40/IL-4- or LPS/IL-4-stimulated B cells. Our data showed that the treatment with 460 was associated with a lower hematological toxicity compared with $1826 S$. In addition, injection with 460 reduced erythema, epidermal thickness, and suppressed IgE and IL-4 synthesis in mice with OVA-induced AD. Additionally, 460 induced TGF- $\beta$ production in LPS/IL-4-stimulated B cells via inhibition of Smad7, which suppressed IgE synthesis via interaction between Id2 and E2A. These findings suggest that enhanced TGF- $\beta$ signaling is an effective treatment for IgE-mediated allergic conditions, and 460 may be safe and effective for treating allergic diseases such as $A D$ and asthma. [BMB Reports 2021; 54(2): 142-147]
\end{abstract}

${ }^{*}$ Corresponding author. Tel: +82-2-2258-7629; Fax: +82-2-3482-8261; E-mail: tykimder@catholic.ac.kr

https://doi.org/10.5483/BMBRep.2021.54.2.254

Received 13 November 2020, Revised 1 December 2020, Accepted 4 January 2021

Keywords: Atopic dermatitis, Id2/E2A interaction, IgE, Phosphodiester CpG-ODN, TGF- $\beta$, Smad7

\section{INTRODUCTION}

Allergic diseases, such as asthma and atopic dermatitis (AD), are closely associated with increased serum immunoglobulin $\mathrm{E}$ (IgE) levels (1). IgE binding to the high-affinity receptor (FC \&RI) in mast cells and basophils induces allergic response. Inhibition of IgE synthesis is an important factor in treating allergic diseases $(2,3)$.

Transforming growth factor- $\beta$ (TGF- $\beta$ ) is a cytokine that acts via the Smad2 and Smad3 pathway to induce cell survival, proliferation, and migration during multiple biological processes, including immune responses, fibrosis, wound healing, and carcinogenesis (4). In an AD model of Smad3-deficient mice, allergen-induced skin inflammation and IgE production were increased (5). Moreover, TGF- $\beta$ is induced by NF- $\kappa B$ activation via TLR9 signaling in prostate cancer cells (6).

CpG-oligodeoxynucleotides (CpG-ODNs) are toll-like receptor 9 (TLR9) agonists, which enhance the anti-cancer efficacy of monoclonal antibodies or cancer vaccines when used as immune adjuvants in various animal models of cancer (7-9). Most TLR9-expressing immune cells, mainly B cells and dendritic cells absorb CpG-ODNs (10). Studies reported that CpG-ODNs prevent T helper 2 (Th2) allergic responses such as antigen-induced asthmatic responses, allergic rhinitis, eczema, and $A D$ (11). CpG-ODNs inhibit the synthesis of interleukin (IL)- 4 , IL-13, and IL- 5 by Th2 cells and trigger Th1 response via induction of interferon (IFN)- $\alpha$ and $-\gamma$, as well as IL-12. In addition, CpG-ODNs inhibit IgE production in B cells (12). However, the mode of action remains unclear.

Synthetic CpG-ODNs mimic the immunostimulatory activity of bacterial DNA, and contain a partial or complete phosphorothioate (PS) backbone, which protects ODN from degradation by nucleases in the body such as DNase, instead of the archetypal phosphodiester (PO) backbone (8). However, CpGODNs with PS backbones induce splenomegaly via B cell proliferation (7), but also trigger the release of TNF- $\alpha$, IL-6, and IL-1 $\beta$ by modulating NF- $\mathrm{KB}$ activation via TLR9 signaling (13). Therefore, patient treatment with PS CpG-ODNs is very limited. However, CpG-ODNs containing a PO backbone (PO

ISSN: 1976-670X (electronic edition)

Copyright (c) 2021 by the The Korean Society for Biochemistry and Molecular Biology

cc) This is an open-access article distributed under the terms of the Creative Commons Attribution Non-Commercial License (http://creativecommons.org/licenses/by-nc/4.0) which permits unrestricted non-commercial use, distribution, and reproduction in any medium, provided the original work is properly cited. 
CpG-ODNs) are more easily degraded by DNase than PS CpG-ODNs. Thus, it is necessary to develop PO CpG-ODNs with an anti-allergic effect and low toxicity.

We sought to identify natural $\mathrm{CpG}$ sequences with a $\mathrm{PO}$ backbone, and $46 \mathrm{O}$ was identified in a previous study (14, 15). In this study, we show that this compound is less toxic and therefore useful for treating allergic diseases. More interestingly, we demonstrated that the anti-allergic effect of $46 \mathrm{O}$ may result from enhanced TGF- $\beta$ signaling via suppression of Smad7, which down-regulated IgE production via induction of Id2/E2A complexes in LPS/IL-4-stimulated B cells. These results imply that induction of TGF- $\beta$ is a useful strategy for treating allergic diseases.

\section{RESULTS}

\section{Low toxicity of 460 compared to $1826 S$ in vivo}

Previous studies reported that CpG-ODNs with a PS backbone, such as 1826S, exhibit immunotoxicity and hepatotoxicity, leading to conditions such as splenomegaly, liver necrosis, and hemorrhagic ascites (16). A low-toxic CpG-ODN with a phosphodiester backbone was synthesized and designated as $46 \mathrm{O}$ (14). To determine the toxicity, $46 \mathrm{O}$ was subcutaneously injected into the mice at concentrations of 67, 200 and 600 $\mathrm{mg} / \mathrm{kg}$ every day for 4 weeks and hematological toxicity was observed at 2 weeks after final treatment with $46 \mathrm{O}$ (Supplementary Table 1). The results showed that $46 \mathrm{O}$ had no hematological toxicity (Supplementary Table 2 and 3). In addition, $46 \mathrm{O}$ and $1826 \mathrm{~S}$ were injected four times into the peritoneal cavity of mice (Fig. 1A). The 18265 CpG-ODN (1826S), which contains a PS backbone, was used as a positive control in vivo. The sizes of the spleen and lymph node increased with $1826 \mathrm{~S}$ treatment. In contrast to $1826 \mathrm{~S}$, 46O-treated mice showed reduce spleen and lymph node masses (Fig. 1B). Moreover, the expression of TNF- $\alpha$ was highly induced in the serum of 1826S-treated mice compared with 46O-treated mice (Fig. 1C).

B cell proliferation by CpG-ODNs is a key mediator of splenomegaly in vivo, and therefore we investigated B cell proliferation via thymidine incorporation in vitro. B cells were isolated from spleen and incubated for $24 \mathrm{~h}$ after treatment with $46 \mathrm{O}$ or $1826 \mathrm{~S}$. As shown in Fig. 1D, $1826 \mathrm{~S}$ treatment increased B cell proliferation, while $46 \mathrm{O}$ treatment did not. We next measured CpG-ODN-induced IL-6 synthesis in B cells by ELISA. As shown in Fig. 1E, treatment with $46 \mathrm{O}$ failed to induce IL-6 production, unlike 1826S. Thus, these results indicate that $46 \mathrm{O}$ is less immunotoxic than $1826 \mathrm{~S}$.

\section{Prevention of antigen (Ag)-induced AD by 460 treatment}

Studies have reported that CpG-ODNs are effective in treating Ag-induced $A D$ (17). However, the preventive role of CpG-ODNs in Ag-induced AD remains unknown. Therefore, we investigated $\mathrm{CpG}$-mediated $\mathrm{AD}$ prevention. We modified the protocol of the Ag-induced AD mouse model established by Kootiratrakarn et al. (17). Before sensitization, $46 \mathrm{O}$ and $1826 \mathrm{~S}$ were administered once, twice, or four times intravenously (Fig. 2A). Balb/c mice were intraperitoneal injected for three times of OVA in alum and along with an occlusive patch of OVA as shown in Fig. 2A. Biopsy specimens were obtained from patchapplied skin one day after completion of epicutaneous sensitization for two weeks. The patch-applied skin was photographed and the injection of $46 \mathrm{O}$ and $1826 \mathrm{~s}$ reduced the skin inflammation phenotype (Fig. 2B). Topical application of OVA in OVA-primed mice indeed induced epidermal hyperplasia and spongiosis with a dense dermal infiltration compared with control mice as analyzed by histological examination of the biopsy samples. Interestingly, treatment with $46 \mathrm{O}$ and $1826 \mathrm{~S}$ reduced OVA-induced epidermal hyperplasia and infiltration of effector cells. This effect was more pronounced when the mice were treated with CpG-ODNs four times compared to

A

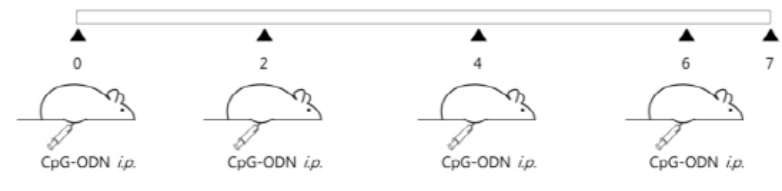

B

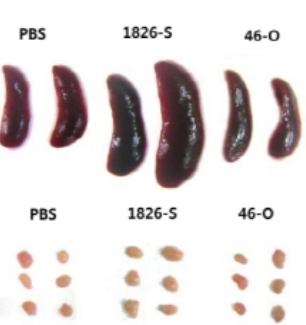

C

D
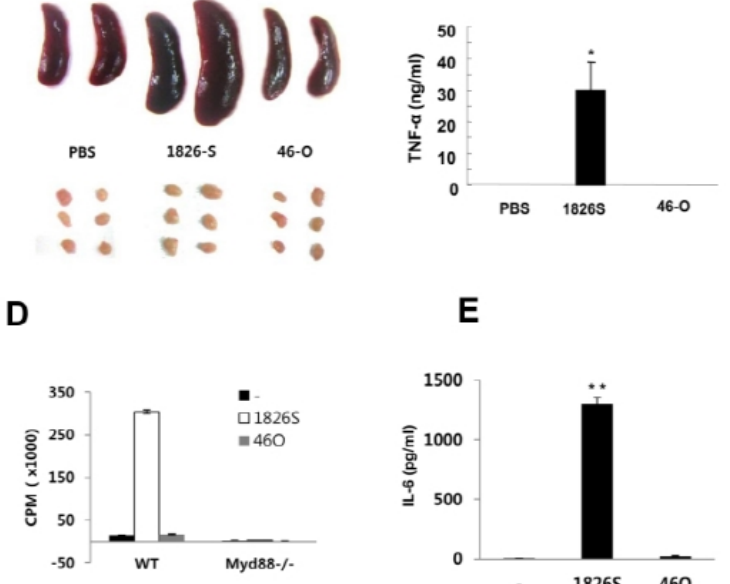

E

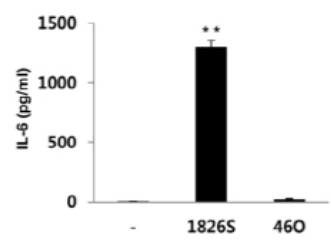

Fig. 1. Toxicity of $46 \mathrm{O}$ CpG-ODNs. (A) Experimental protocol for the analysis of toxicity induced by CpG-ODNs. (B) The spleen and lymph nodes of mice treated with $46 \mathrm{O}$ or $1826 \mathrm{~S}$ CpG-ODN. (C) TNF- $\alpha$ expression in the serum of 460 or $1826 \mathrm{~S}$ CpG-ODN-treated mice was determined by ELISA. (D) $\left[{ }^{3} \mathrm{H}\right]$-thymidine incorporation assays of splenic B cells derived from $46 \mathrm{O}$ or $1826 \mathrm{~S}$ CpGODN-treated mice for $24 \mathrm{~h}$. (E) IL-6 production in splenic B cells of $46 \mathrm{O}$ or $1826 \mathrm{~S}$ CpG-ODN-treated mice was measured in the culture supernatant by ELISA; $* P<0.05$ and $* * P<0.01$, versus PBS-treated mice. 


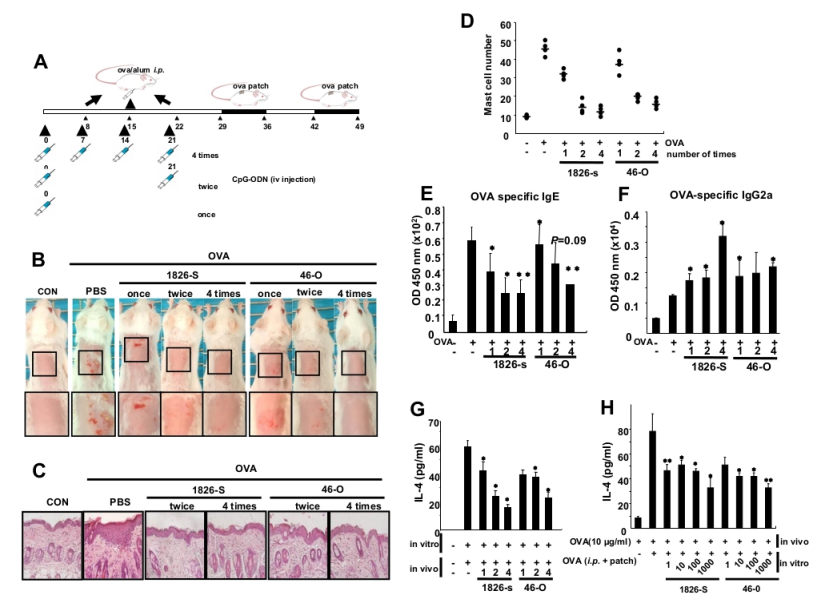

Fig. 2. Treatment with $46 \mathrm{O} \mathrm{CpG-ODN}$ prevents Ag-induced $\mathrm{AD}$ and IgE secretion. (A) Experimental protocol for in vivo studies to test the efficacy of CpG-ODNs in an Ag-induced AD mouse model. (B) Phenotypical presentation of OVA patch sites. (C) Hematoxylin and eosin staining of the skin (200× magnification). (D) Mast cell infiltration was analyzed by toluidine blue staining and counted per $400 \times$ field by two independent researchers. Expression of OVA-specific (E) IgE and (F) IgG2a secretions in the serum of experimental mice was analyzed by ELISA. (G) Splenocytes were isolated from experimental mice and cultured with $10 \mu \mathrm{g} / \mathrm{ml}$ OVA protein for $48 \mathrm{~h}$. IL-4 production was analyzed by ELISA. (H) In vitro analysis of IL-4 synthesis in OVA-activated splenocytes following $46 \mathrm{O}$ treatment. Splenocytes were purified from PBS-treated mice and cultured in the presence or absence of $1826 \mathrm{~S}$ and $46 \mathrm{O}$. After $48 \mathrm{~h}, \mathrm{IL}-4$ was measured in the cell-free culture medium by ELISA; $* P<0.05$ and $* * P<0.01$, versus no treatment with CpG-ODN. Data are expressed as mean \pm standard deviation.

twice (Fig. 2C). Besides IgE and IL-4 production, mast cells play an important role in allergic diseases (2). The mast cells in the skin were quantified by toluidine blue staining. The number of mast cells per $400 \times$ microscopic field in the infiltrated dermal area was five-fold higher in OVA-induced $\mathrm{AD}$ skin, and this induction was decreased by both CpGODNs in a dose-dependent manner (Fig. 2D).

\section{IgE inhibition by 460 treatment in antigen-induced AD}

$\mathrm{IgE}$ is an important factor in AD pathogenesis (18). Therefore, we investigated whether pre-treatment with $46 \mathrm{O}$ prevented IgE production. We collected sera at the time of skin biopsy and then measured the total and OVA-specific IgE production by ELISA. Similar to the histological results, pre-treatment with $46 \mathrm{O}$ or $1826 \mathrm{~S}$ significantly decreased OVA-specific IgE in a CpG-ODN dose-dependent manner (Fig. 2E). However, these compounds increased OVA-specific IgG2a (Fig. 2F).

Since IL-4 plays an important role in Th2-mediated diseases such as AD, we analyzed OVA-specific IL-4 production in vitro. We isolated splenocytes from the biopsy specimens and then cultured them with $10 \mu \mathrm{g} / \mathrm{ml}$ OVA protein. After $48 \mathrm{~h}$,
A
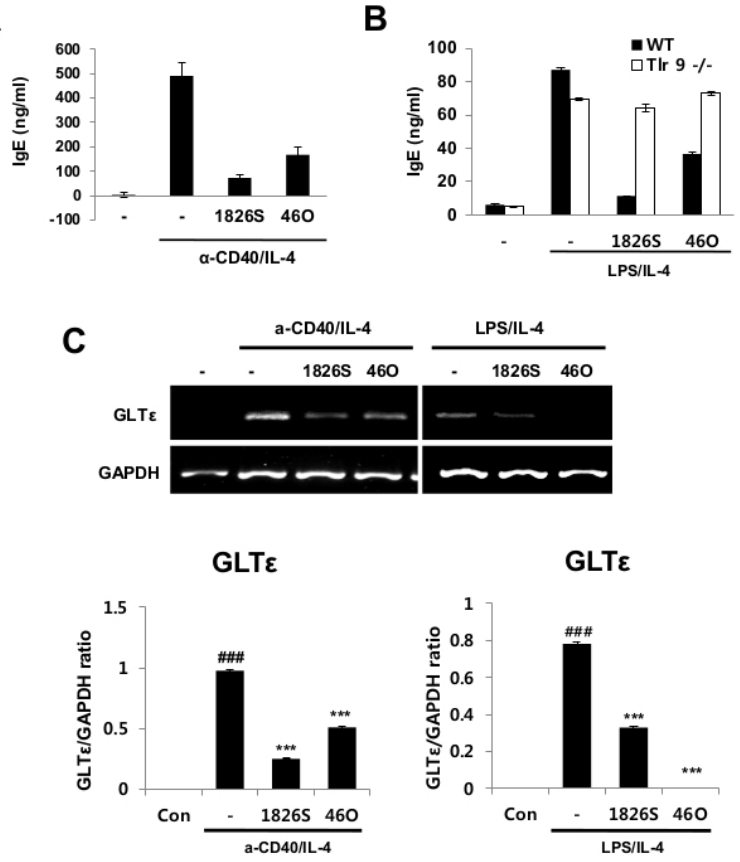

Fig. 3. Inhibitory effect of $46 \mathrm{O}$ on IgE production. (A) B cells isolated from the spleen of Balb/c mice were cultured for 5 days with CPG-ODNs, in the presence of LPS/IL-4 or anti-CD40/IL-4. The level of IgE was determined by ELISA. (B) Inhibition of IgE synthesis by $46 \mathrm{O}$ via TLR9. B cells were purified from spleens of Balb/c or TLR9 knockout mice and then cultured with $1826 \mathrm{~S}$ or $46 \mathrm{O}$ in the presence of LPS/IL-4 or anti-CD40/IL-4 for 5 days. IgE levels were assessed by ELISA. (C) Level of C $\varepsilon$ GLT in B cells. Splenic B cells were activated by LPS/IL-4 or anti-CD40/IL-4 and then cultured with CpG-ODNs, including $1826 \mathrm{~S}$ or $46 \mathrm{O}$, for 3 days. The level of CE GLT mRNA was quantified by RT-PCR; *P $<0.05$ and $* * P<0.01$, versus positive control. Data are representative of three independent experiments.

IL-4 was measured in the culture medium. The level of IL-4 secretion decreased in splenocytes derived from CpG-ODNtreated mice compared with PBS-treated control mice (Fig. 2G) in a dose-dependent manner. Additionally, splenocytes isolated from PBS-treated mice were cultured with CpG-ODNs in vitro. As shown in Fig. $2 \mathrm{H}, 46 \mathrm{O}$ treatment inhibited IL-4 secretion in isolated splenocytes from PBS-treated mice in vitro. These results showed that $46 \mathrm{O}$ is not only a potential therapeutic agent but also prevents Ag-induced AD.

\section{Inhibition of IgE production in B cells by $\mathbf{4 6 O}$}

IgE synthesis in B cells requires two signals (19). The first signal is provided by cytokine IL-4 and the second signal is provided by ligation of CD40 on B cells. Lipopolysaccharide (LPS) can mimic CD40 ligation in vitro. To evaluate the inhibitory effect of $46 \mathrm{O}$ on IgE synthesis, B cells were cultured for 5 days with LPS or CD40 ligand (CD154) in the presence of IL-4, and the IgE production in the culture media was 
measured. As shown in Fig. 3A, IgE synthesis was decreased significantly by both $1826 \mathrm{~S}$ and $46 \mathrm{O}$ treatment in CD40/IL-4or LPS/IL-4-treated B cells. However, IgE synthesis was not decreased by CpG-ODNs in TLR9 ${ }^{-/}$B cells (Fig. 3B). Additionally, we also determined the transcription level of GLT $\varepsilon$, which is responsible for IgE class switching. Our data demonstrate that the level of GLTE mRNA was reduced by $46 \mathrm{O}$ and $1826 \mathrm{~S}$ in CD40/IL-4- or LPS/IL-4-treated B cells (Fig. 3C).

\section{Inhibition of IgE production via 46O-induced Id2/E2A complex formation in LPS/IL-4-activated B cells}

To investigate the inhibitory mechanism of $46 \mathrm{O}$ in $\operatorname{lgE}$ secretion, we investigated whether this compound regulated TGF- $\beta$ signaling because TGF- $\beta$ suppressed IgE levels in AD-like skin lesions and serum in the NC/Nga mouse model (20). TGF- $\beta$ expression was measured in culture media using ELISA. Fig. $4 \mathrm{~A}$ and $\mathrm{B}$ showed that treatment with $46 \mathrm{O}$ and $1826 S$ induced TGF- $\beta$ secretion from CD40/IL-4- and LPS/IL-4-treated B cells. The level of TGF- $\beta$ mRNA was also increased by treatment with both CpG-ODNs (Fig. 4C). Next, we analyzed the Smad7 mRNA level via quantitative real-time PCR because Smad7 is a known suppressor of TGF- $\beta$ signaling (21). B cells were treated with LPS or CD40 ligand (CD154) in the presence of IL-4 for 3 days and RNA was extracted from B cells. As shown in Fig. 4D, the expression of Smad7 mRNA was decreased by both $46 \mathrm{O}$ and $1826 \mathrm{~S}$ in LPS/IL-4- and CD40/IL-4-stimulated B cells. Since both CpG-ODNs slightly suppressed Smad7 expression in CD40/IL-4-activated B cells, we investigated the role of CpG-ODN and TGF- $\beta$ signaling in IgE production by LPS/IL-4-activated B cells. LPS/IL-4-activated B cells were incubated with or without LY364947, a TGF- $\beta$ inhibitor. Treatment with LY364947 abrogated the 46O-induced IgE suppression in B cells (Fig. 4E). However, LY364947 could not reverse the 1826S-induced IgE suppression, suggesting that $46 \mathrm{O}$, but not $1826 \mathrm{~S}$ inhibits IgE synthesis via TGF- $\beta$ signaling in LPS/IL-4-activated-B cells.

Finally, we performed immunoprecipitation with an anti-ld2 antibody using lysates of 46O-treated B cells to elucidate the mechanism by which $46 \mathrm{O}$ inhibits IgE production via TGF- $\beta$ up-regulation. E2A binds to the E-Box in the $\varepsilon$ germline promoter, which promotes class switch recombination (CSR) to IgE. Id 2 acts as a negative regulator of basic helix-loop-helix $(\mathrm{bHLH})$ transcription factors, such as E2A, by antagonizing E2A activity (22). To establish Id2 and E2A complex formation, $\mathrm{B}$ cells were cultured with or without $46 \mathrm{O}$ in the presence of LPS/IL-4, and the cell lysates were harvested. As shown in Fig. $4 \mathrm{~F}$, $46 \mathrm{O}$ treatment enhanced Id2/E2A complex formation, as well as Id2 expression in LPS/IL-4-activated B cells. Therefore, our data demonstrate that $46 \mathrm{O}$ inhibited IgE synthesis by increasing Id 2 expression and binding to E2A.

\section{DISCUSSION}

Synthetic PS CpG-ODNs contain a partial or complete PS
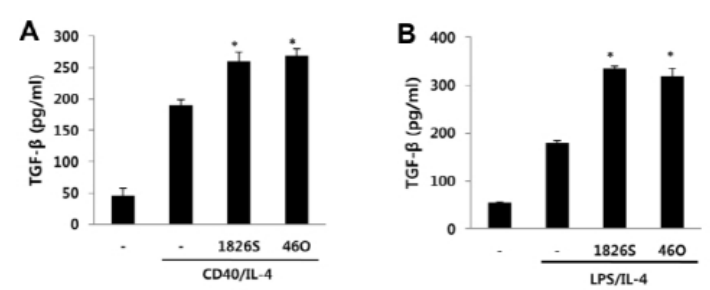

C
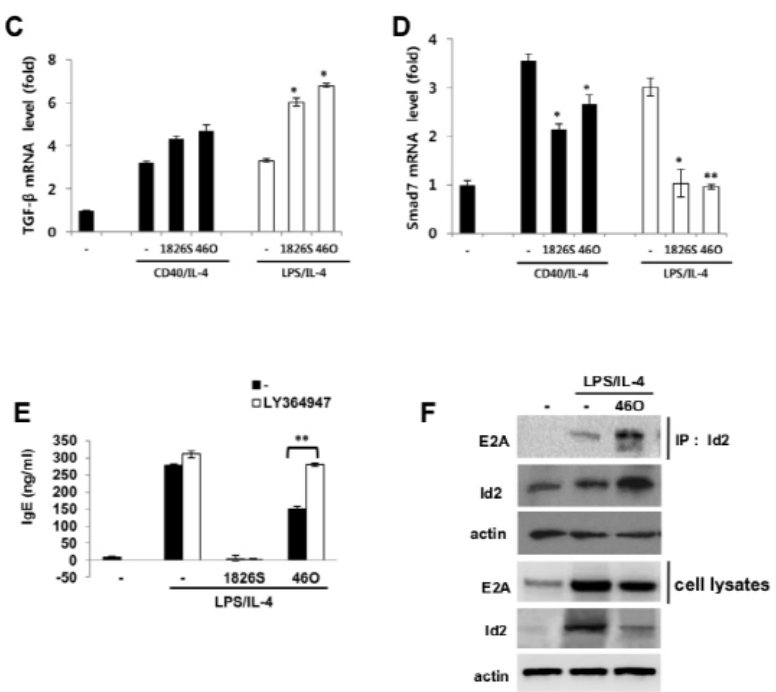

Fig. 4. Inhibition of IgE by 460 mediated via TGF- $\beta$ induction in LPS/IL-4-activated $B$ cells. TGF- $\beta$ induction by CPG-ODNs, including $1826 \mathrm{~S}$ and $46 \mathrm{O}$, in $\mathrm{B}$ cells treated with (A) antiCD40/IL-4 and (B) LPS/IL-4. B cells were cultured for 4 days. TGF- $\beta$ expression in the culture supernatant was measured by ELISA. (C) Induction of TGF- $\beta$ mRNA level in B cells. (D) Inhibition of Smad7 mRNA level by CpG-ODNs, including $1826 \mathrm{~S}$ and $46 \mathrm{O}$. $\mathrm{B}$ cells were cultured in the presence of anti-CD40/IL-4 or LPS/IL-4 for 3 days. Levels of TGF- $\beta$ and Smad7 mRNA were analyzed by quantitative real-time PCR. (E) LY364947 reverses 46O-induced IgE suppression in LPS/IL-4-stimulated B cells. IgE in $B$ cells was measured in cultured media for 5 days using ELISA. (F) Immunoprecipitation (IP) of Id2/E2A complexes. B cells were cultured with or without $46 \mathrm{O}$ in the presence of LPS/IL-4 for 5 days. B cell lysates were immune precipitated with anti-ld2 antibody or the respective control. $* \mathrm{P}<0.05$ and $* * \mathrm{P}<0.01$, versus positive control. Data are representative of three independent experiments.

backbone instead of the archetypal PO backbone to protect the ODN from degradation by DNases in the body (8). CpG-ODNs are strong Th1 response inducers while inhibiting Th2 responses, and therefore CpG-ODNs are considered as adjuvant treatment for Th2-mediated allergy (7). Despite significant advances in treating Th2 allergic disease using these compounds as therapeutic adjuvants, the clinical use of PS CpG-ODNs is restricted by side effects such as megalosplenia, pro-inflammatory cytokine release, and lymphoid follicle destruction (23). Therefore, the development of less toxic CpG- 
ODNs is necessary. In the present study, we showed that $46 \mathrm{O}$, which carries a PO backbone, did not induce megalosplenia and secreted lower levels of pro-inflammatory cytokines than 1826S, a PS CpG-ODN.

CpG-ODNs inhibit IgE synthesis in B cells, a process that requires two signals (19). The first signal is provided by IL-4, which activates transcription at a specific Ig locus. The second signal is provided by the ligation of CD40 on B cells, which in turn activates DNA switch recombination. This signal can be also provided by LPS instead of CD40 in vitro. Liu et al. showed that PS CpG-ODN directly up-regulates T-bet expression in CD40/IL-4-stimulated B cells and T cells, resulting in IgE suppression (24). However, it remains to be elucidated how PO CpG-ODN inhibits IgE production in LPS/IL-4-stimulated B cells.

In this study, we revealed a novel mechanism involving PO CpG-ODN-induced IgE inhibition via TGF- $\beta$ signaling in LPS/IL4-stimulated B cells. Oral administration of high doses of TGF- $\beta$ inhibits serum IgE in an OVA-induced allergy model (25). Another study demonstrated that CpG-ODN promotes IL-8 and TGF- $\beta 1$ via NF- $\kappa$ B activation in prostate cancer cells (26). TGF- $\beta$ signaling inhibits IgE synthesis and AD (20). Consequently, TGF- $\beta$ signaling was investigated as a possible target of $46 \mathrm{O}$ in IgE inhibition. Indeed, 46O-induced TGF- $\beta$ signaling inhibited IgE synthesis in B cells activated by stimulation with LPS/IL-4 or CD40/IL-4. To elucidate the mechanism of TGF- $\beta$ induction by $46 \mathrm{O}$, we investigated Smad7 expression, which plays an essential role in the negative feedback regulation of TGF- $\beta$ signaling by inhibiting TGF- $\beta$ receptors (21). Here, we showed that Smad7 mRNA was suppressed dramatically by $46 \mathrm{O}$ treatment in LPS/IL-4-stimulated B cells. LY364947, a TGF- $\beta$ inhibitor, rescued 46O-induced IgE suppression; however, this response was not mediated by $1826 \mathrm{~S}$ in LPS/IL-4-treated B cells. These results suggest that the inhibitory mechanism of $46 \mathrm{O}$ differs from that of $1826 \mathrm{~S}$ and only $46 \mathrm{O}$ inhibits IgE synthesis via TGF- $\beta$ signaling in LPS/IL4-activated-B cells. Thus, $1826 \mathrm{~S}$ and $46 \mathrm{O}$ may have different modes of action and the inhibitory mechanism of 1826 may be mediated via modulation of other signals rather than TGF- $\beta$. However, a comprehensive study is required to delineate the inhibitory mechanism of 1826 s on IgE production. Finally, we investigated the regulation of Id2/E2A complex formation in 46O-treated $\mathrm{B}$ cells to further elucidate the mechanism by which $46 \mathrm{O}$ inhibits IgE via TGF- $\beta$ up-regulation. E2A binds to the E-Box within the $\varepsilon$ germline promoter, which promotes IgE class switch recombination (CSR) (27) and is negatively regulated by Id2 via Id2-E2A interaction. Further, E2A binds strongly to E-boxes within the $\varepsilon$ germline promoter in $\mathrm{Id} 2-$ deficient mice (28). Interestingly, TGF- $\beta$ can induce Id2 (29). Therefore, we investigated whether $46 \mathrm{O}$ induced Id2/E2A interaction via TGF- $\beta$ induction. As expected, 460 inhibited IgE CSR by increasing Id 2 via enhanced TGF- $\beta$ signaling in LPS/IL-4-stimulated B cells.

We previously reported the therapeutic effects of topical application of $46 \mathrm{O}$ in allergic Th2 responses using a mouse model of AD (30). In this study, we demonstrated for the first time the detailed mechanism of the preventive effects of 460 against allergic diseases. Several studies have reported that OVA stimulation, together with aluminum, induces release of OVA-specific IgE, which represents a switch to induction of allergic Th2 responses (31). In the present study, $46 \mathrm{O}$ was administered once, twice, or four times intravenously before sensitization. Treatment with $46 \mathrm{O}$ inhibited IL-4 secretion in IgE-secreting plasma cells isolated from PBS-treated mice in vitro as well as OVA-specific synthesis of IgE and IL-4 in sera. Moreover, the toxicity of $46 \mathrm{O}$, as measured by the occurrence of splenomegaly and TNF- $\alpha$ production, was significantly lower compared to that of $1826 \mathrm{~S}$. These results indicate that $46 \mathrm{O}$ pre-treatment can prevent the Th2 response in allergic diseases without cytotoxicity.

Taken together, we demonstrated that $46 \mathrm{O}$ treatment prevents allergic responses by up-regulating TGF- $\beta$ via suppression of Smad7, which inhibits IgE synthesis by inducing Id2/E2A complex formation in LPS/IL-4-stimulated B cells. Therefore, our data suggest that $46 \mathrm{O}$ may be a safe and effective therapeutic candidate for treatment of allergic diseases such as $\mathrm{AD}$ and asthma.

\section{MATERIALS AND METHODS}

Detailed information is provided in the Supplementary Information.

\section{ACKNOWLEDGEMENTS}

This study was supported by the Bio \& Medical Technology Development Program of the NRF funded by the Korean government, MSIP (NRF-2016M3A9B6903020) and the Korea Health Technology R\&D Project through the Korea Health Industry Development Institute (KHIDI), funded by the Ministry of Health \& Welfare, Republic of Korea (grant number: HI06C0805).

\section{CONFLICTS OF INTEREST}

The authors have no conflicting interests.

\section{REFERENCES}

1. Eibensteiner $P$, Spitzauer $S$, Steinberger $P$, Kraft $D$, Valenta $R$ (2000) Immunoglobulin $E$ antibodies of atopic individuals exhibit a broad usage of $\mathrm{VH}$-gene families. Immunology 101, 112-119

2. Calman Prussin DDM (2003) IgE, mast cells, basophils, and eosinophils. J Aller Clin Immunol 111, S486-494

3. Gould HJ, Sutton BJ (2008) IgE in allergy and asthma today. Nat Rev Immunol 8, 205-217

4. Li MO W, Sanjabi S, Robertson AK, Flavell RA (2006) Transforming growth factor-h regulation of immune responses. Annu Rev Immunol 24, 99-146 
5. Anthoni M, Wang G, Deng C, Wolff HJ, Lauerma Al, Alenius HT (2007) Smad3 signal transducer regulates skin inflammation and specific IgE response in murine model of atopic dermatitis. J Invest Dermatol 127, 1923-1929

6. Jin-ming $\mathrm{Di}$ JP, Xiao-yong Pu, Yan Zhang et al (2009) Toll-like receptor 9 agonists promote IL-8 and TGF-b1 production via activation of nuclear factor $\mathrm{kB}$ in PC-3 cells. Cancer Genet Cytogenet 192, 60-67

7. Bhagat L, Zhu FG, Yu D et al (2003) CpG penta- and hexadeoxyribonucleotides as potent immunomodulatory agents. Biochem Biophys Res Commun 300, 853-861

8. Alexander H, Dalpke SZ, Albrecht I, Heeg K (2002) Phosphodiester CpG oligonucleotides as adjuvants: polyguanosine runs enhance cellular uptake and improve immunostimulative activity of phosphodiester CpG oligonucleotides in vitro and in vivo. Immunology 106, 102-112

9. Verthelyi D, Kenney RT, Seder RA, Gam A, Friedag B, Klinman DM (2002) CpG oligodeoxynucleotides as vaccine adjuvants in primates. J Immunol 168, 1659-1663

10. Jiang W, Lederman M, Harding CV, Rodriguez B, Mohner RJ, Sieg SF (2007) TLR9 stimulation drives naive B cells to proliferate and to attain enhanced antigen presenting function. Eur J Immunol 37, 2205-2213

11. Serebrisky D, Teper AA, Huang CK et al (2000) CpG oligodeoxynucleotides can reverse Th2-associated allergic airway responses and alter the B7.1/B7.2 expression in a murine model of asthma. J Immunol 165, 5906-5912

12. Kusunoki T, Sugai $M$, Gonda $\mathrm{H}$ et al (2005) CpG inhibits IgE class switch recombination through suppression of NF kappa B activity, but not through Id2 or Bcl6. Biochem Biophys Res Commun 328, 499-506

13. Tsujimura $H$, Tamura $T$, Kong $H J$ et al (2004) Toll-like receptor 9 signaling activates NF-kappaB through IFN regulatory factor-8/IFN consensus sequence binding protein in dendritic cells. J Immunol 172, 6820-6827

14. Choi YJ, Lee KW, Kwon HJ, Kim DS (2006) Identification of immunostimulatory oligodeoxynucleotide from Escherichia coli genomic DNA. J Biochem Mol Biol 39, 788-793

15. Park S, Kim K, Na K, Kim Y, Kim T (2007) Effect of dendritic cells treated with $\mathrm{CpG}$ ODN on atopic dermatitis of $\mathrm{Nc} / \mathrm{Nga}$ mice. J Biochem Mol Biol 40, 486-493

16. Heikenwalder M, Polymenidou M, Junt T et al (2004) Lymphoid follicle destruction and immunosuppression after repeated $\mathrm{CpG}$ oligodeoxynucleotide administration. Nat Med 10, 187-192

17. Kootiratrakarn T, Fujimura T, Sano K et al (2005) Development of a novel Ag-specific immunotherapy using CpG oligodeoxynucleotides in a new, unique mouse cutaneous eosinophilic inflammation model. Eur J Immunol 35, 3277-3286

18. Geha RS, Jabara HH, Brodeur SR (2003) The regulation of immunoglobulin E class-switch recombination. Nat Rev Immunol 3, 721-732

19. Yanagihara $Y(1999)$ Molecular regulation of human IgE synthesis. Allergol Int 48, 111-119

20. Sumiyoshi K, Nakao A, Ushio H et al (2002) Transforming growth factor-beta1 suppresses atopic dermatitis-like skin lesions in NC/Nga mice. Clin Exp Allergy 32, 309-314

21. Suping Zhang TF, Lixia Zhang, Ran Zhang et al (2007) Smad7 antagonizes TGF- $\beta$ signaling in the nucleus by interfering with functional Smad-DNA complex formation. Mol Cell Biol 27, 4488-4499

22. Sugai $M$, Gonda $H$, Kusunoki $T$, Katakai $T$, Yokota $Y$, Shimizu A (2003) Essential role of Id 2 in negative regulation of $\mathrm{IgE}$ class switching. Nat Immunol 4, 25-30

23. Heikenwalder M, Polymenidou M, Junt T et al (2004) Lymphoid follicle destruction and immunosuppression after repeated $\mathrm{CpG}$ oligodeoxynucleotide administration. Nat Med 10, 187-192

24. Liu N, Ohnishi N, Ni L, Akira S, Bacon KB (2003) CpG directly induced T-bet expression and inhibits $\operatorname{lgG} 1$ and IgE switching in B cells. Nat Immunol 4, 687-693

25. Okamoto A, Kawamura T, Kanbe K et al (2005) Suppression of serum IgE response and systemic anaphylaxis in a food allergy model by orally administered high-dose TGF-beta. Int Immunol 17, 705-712

26. Di J, Pang J, Pu X et al (2009) Toll-like receptor 9 agonists promote IL-8 and TGF-beta1 production via activation of nuclear factor kappaB in PC-3 cells. Cancer Genet Cytogenet 192, 60-67

27. Quong MW, Harris DP, Swain SL, Murre C (1999) E2A activity is induced during B-cell activation to promote immunoglobulin class switch recombination. EMBO J 18, 6307-6318

28. Sugai $M$, Gonda $H$, Kusunoki $T$, Katakai $T$, Yokota $Y$, Shimizu A (2003) Essential role of Id2 in negative regulation of IgE class switching. Nat Immunol 4, 25-30

29. Sugai $M$, Gonda $H$, Nambu $Y$, Yokota $Y$, Shimizu A (2004) Role of Id proteins in B lymphocyte activation: new insights from knockout mouse studies. J Mol Med 82, 592-599

30. Kim Y, Lee K, Kwon H, Kim D, Kim T (2007) Improvement of atopic dermatitis in NC/Nga mice by topical application of CpG phosphodiester-ODN. Int Arch Aller Immunol $144,315-324$

31. Nabe T, Zindl CL, Jung YW et al (2005) Induction of a late asthmatic response associated with airway inflammation in mice. Eur J Pharmacol 521, 144-155 